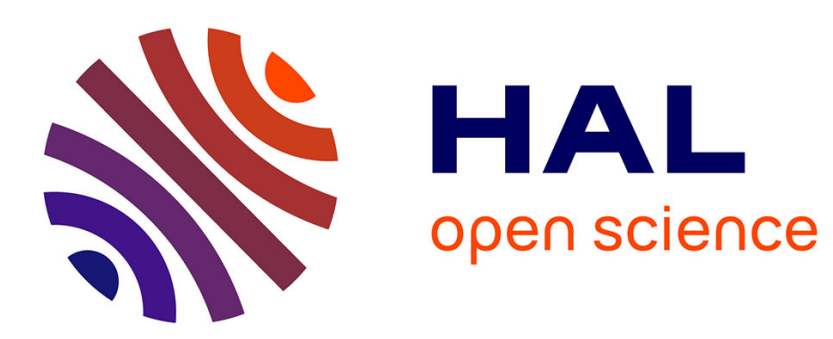

\title{
Design of a large field-of-view see-through near to eye display with two geometrical waveguides
} Jianming Yang, Patrice Twardowski, Philippe Gérard, Joël Fontaine

\section{To cite this version:}

Jianming Yang, Patrice Twardowski, Philippe Gérard, Joël Fontaine. Design of a large field-of-view see-through near to eye display with two geometrical waveguides. Optics Letters, 2016, 41 (23), pp.5426-5429. 10.1364/OL.41.005426 . hal-02064485

\section{HAL Id: hal-02064485 \\ https://hal.science/hal-02064485}

Submitted on 11 Mar 2019

HAL is a multi-disciplinary open access archive for the deposit and dissemination of scientific research documents, whether they are published or not. The documents may come from teaching and research institutions in France or abroad, or from public or private research centers.
L'archive ouverte pluridisciplinaire HAL, est destinée au dépôt et à la diffusion de documents scientifiques de niveau recherche, publiés ou non, émanant des établissements d'enseignement et de recherche français ou étrangers, des laboratoires publics ou privés. 


\title{
Design of a large field-of-view see-through near to eye display with two geometrical waveguides
}

\author{
Jianming Yang, ${ }^{1,2,}{ }^{*}$ Patrice TWardowski, ${ }^{1}$ Philippe Gérard, ${ }^{1}$ And JoËl Fontaine ${ }^{1}$ \\ ${ }^{1}$ ICube UMR-7357, CNRS, University of Strasbourg, INSA, Strasbourg-IIlkirch, France \\ ${ }^{2}$ Changchun Institute of Optics, Fine Mechanics and Physics, Chinese Academy of Sciences, Changchun, Jilin 130033, China \\ *Corresponding author: jianming.yang@unistra.fr
}

Received XX Month XXXX; revised XX Month, XXXX; accepted XX Month XXXX; posted XX Month XXXX (Doc. ID XXXXX); published XX Month XXXX

\begin{abstract}
A novel waveguide near to eye display (WGNED), with new in-coupling and propagation subsystems, is proposed for the first time to enlarge the vertical field-ofview (FOV) and the vertical size of the eye box. Two waveguides are stacked, one is for in-coupling and the other for out-coupling. A freeform prism is used to correct the aberrations. These components are combined together to form the WGNED. We have simulated such a system; as a result, we show that it achieves a FOV of $30^{\circ}$ Horizontal (H) $\times 60^{\circ}$ Vertical (V) and an eye box of about $15 \mathrm{~mm}(\mathrm{H}) \times 12 \mathrm{~mm}(\mathrm{~V})$. The modulation transfer function (MTF) of the system is larger than 0.3 at 33 $\mathrm{lp} / \mathrm{mm}$ and the distortion is smaller than $5 \%$. (C) 2016 Optical Society of America
\end{abstract}

OCIS codes: (080.2740) Geometric optical design, (120.2040) Displays, (220.4610) Optical fabrication, (350.4600) Optical engineering,

(330.7321) Vision coupled optical systems.

http://dx.doi.org/10.1364/OL.99.099999

In the past few years, near to eye displays (NEDs) have undergone rapid developments [1] with the release of a series of related commercial products, such as Microsoft HoloLens [2], Google Glasses [3], products of Sony [4] and Nokia [5]. NEDs can be classified as see-through which is for augmented reality (AR) and immersive that is for virtual reality (VR). For AR, see-through NEDs have the capability of superimposing a virtual image on the real world scene; the virtual image and the real world scene are seen simultaneously by the user [6]. There are various approaches to realize see-through systems such as using freeform optical prisms [7], projection systems [8, 9], adaptive correcting optics [10], retinal scanning [11], reflective system [12], hybrid reflectiverefractive system [13] and optical waveguides [14-15]. A very detailed review can be found in the literature [16, 17]. Main requirements for such systems are compactness and lightness. However, it is a very difficult task to meet these criteria and keep high performance at the same time. The field-of-view (FOV) and the eye box are two of the key parameters to evaluate the optical performance of a NED. Each technology has its own constraints.
According to the combiner type, NEDs can be separated into two families [16]: one is free space combiner that has no capability to expand pupil size, the other is waveguide combiner which can expand pupil size without increasing Lagrange invariant. Therefore, the use of waveguide can reduce the design difficulties and probably is the most promising approach. Waveguide technology can be classified into two types: geometrical waveguides and holographic waveguides. Both of them consist of input-coupling and output-coupling subsystem. Lumus company employs a reflective mirror for the input-coupling optics and an array of partially reflective mirrors (PRMA) for the outputcoupling optics [18]. The PRMA is specially designed to have the right reflectance for different wavelengths and angles. Optinvent company uses small cascaded mirrors as out-coupling subsystem because the focus point of eye is far from the mirrors [19]. Microsoft [2], Konica Minolta [20], Sony and BAE Systems [21, 22] corporations have used diffractive optical elements (DOEs) or holographic optical elements (HOEs) to develop their WGNED. However, having large FOV in both horizontal and especially in vertical direction is a difficult problem in WGNEDs. Horizontally, the FOV is limited by three parameters: the total internal reflection angle of the material of the waveguide, the expanded pupil size and the distance between each reflection inside the waveguide. Normally, horizontal FOV reaches around $20^{\circ}$ inside the waveguide and $30^{\circ}$ in air. As light from a pupil propagates along the waveguide divergently, vertical FOV is greatly dependent on the pupil size in this direction in order to reach the eye. It is about $9^{\circ}$ with a pupil size of $8 \mathrm{~mm}$ from the equation proposed in [14]. In order to enlarge the FOV vertically, Amitai [14] proposed a twodimensional aperture expanding method using cascaded mirrors. Using the same concept Eisen et al. [23] proposed a system with three holographic gratings for in-coupling light into the waveguide and expanding the eye box along orthogonal directions. Microsoft corporation has also adopted this concept to develop HoloLens [2]. However, the FOV does not exceed $40^{\circ}$. Cheng [15] proposed a two-pupil design by combining the freeform prism and waveguide together to address this problem. Using this method, Han [24] designs a similar system with a $18^{\circ}(\mathrm{H}) \times 24^{\circ}(\mathrm{V})$ FOV. In this paper we introduce a new method that can increase the vertical FOV to $60^{\circ}$ and enlarge the vertical size of the eye box to $12 \mathrm{~mm}$. Using 
cascaded mirrors as Lumus waveguide type, the horizontal size of the eye box can be expanded to $15 \mathrm{~mm}$. The total FOV is then $30^{\circ}$ $(\mathrm{H}) \times 60^{\circ}(\mathrm{V})$ with a total eye box of $15 \mathrm{~mm}(\mathrm{H}) \times 12 \mathrm{~mm}(\mathrm{~V})$, which is, to our knowledge, the largest FOV among the published WGNEDs.

Fig. 1 shows the structure of the system and the ray path inside. Two waveguides are stacked up with a small air gap so that light can propagate inside the two waveguides independently. The light emitted by the micro-display is coupled into the first waveguide by the in-coupling subsystem. Light propagates inside the first waveguide until reaching a cylindrical mirror at the end of the waveguide. In the area near the mirror, the two waveguides are combined together. Then, the light reflected by the cylindrical mirror is coupled into the second waveguide. Using existing method such as hologram or cascaded mirrors, the light is coupled out from the second waveguide. The in-coupling system consists of a prism with four different optical freeform surfaces (from S2 to S5) and a lens made of a freeform surface (S1) and a plane surface. This complex prism gives more freedom to correct aberrations. Moreover, it can be fabricated in one piece. As the FOV in horizontal direction is limited to $30^{\circ}$ in air, the total light section is small; as a consequence, S2 and S4 surfaces can be separated. The in-coupling pupil has a rectangular shape with a size of $1.9 \mathrm{~mm}(\mathrm{H})$ $\times 12 \mathrm{~mm}(\mathrm{~V})$ which acts as a stop aperture and then greatly reduces the stray light. Pupil size is enlarged by adding vignetting along $z$ direction as shown in Fig. 1(b) and (c).

The center $O$ of the in-coupling pupil, shown in Fig.2(a), is the center of the cylindrical mirror and also the center of the cylindrical edge of the air gap. After the reflection, the chief ray of each field will go backward and converge to a point. The associated propagating length is the radius of the cylindrical mirror. The position of the eye should be near this point, so that each field can be seen as shown in Fig. 1(c).

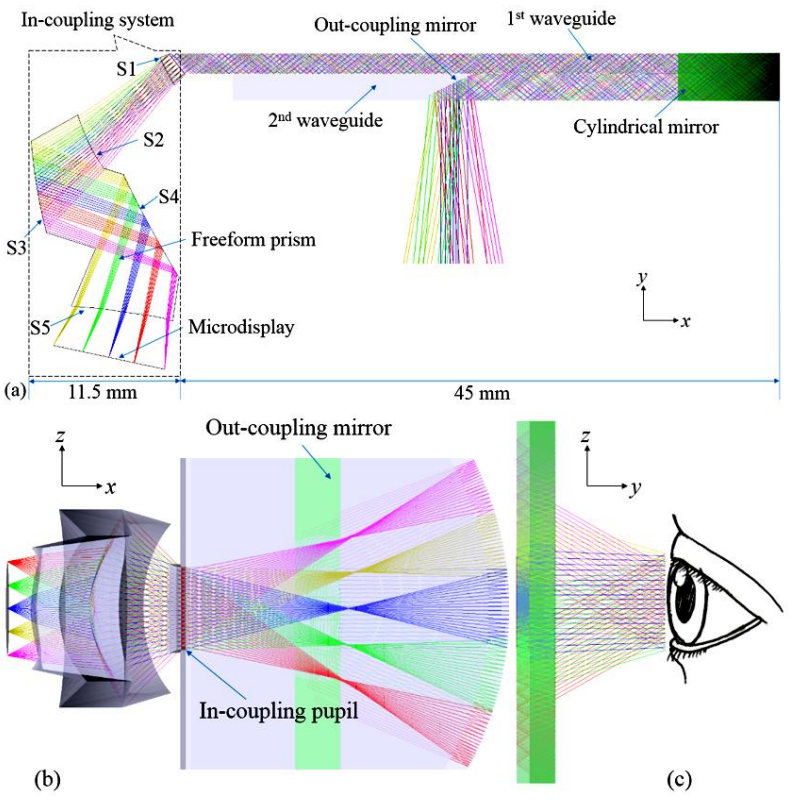

Fig. 1. The whole structure and optical path of the proposed system from different points of view: (a) yx view, (b)zx view, (c)zy view.
The focal property of light after the in-coupling pupil is different in zx plane and yx plane because of the cylindrical mirror which is shown in Fig. 2. We suppose that the radius of the mirror is $R$. In the case of paraxial approximation, rays converge to the focal plane of the cylindrical mirror which is located at $R / 2$ from the center in zx plane as shown in Fig. 2(a). Then rays are reflected by the cylindrical mirror and become a parallel beam that is coupled into the second waveguide. However, as the cylindrical mirror has no optical power in yx plane, the light should be a parallel beam after the in-coupling pupil as shown in Fig. 2(b). To compensate the large optical power caused by the cylindrical mirror, we use a freeform prism and a lens to correct aberrations, in which all the surfaces are XY polynomials. The optical power in yx plane is mainly given by the mirror S3 (Fig.1(a)). The advantage of this design is a large pupil size $(12 \mathrm{~mm})$ in $\mathrm{z}$ direction with high image quality. Using the in-coupling system mentioned above, the beam then becomes parallel in both directions after the reflection from the cylindrical mirror. Finally, it is coupled out to the user's eye.

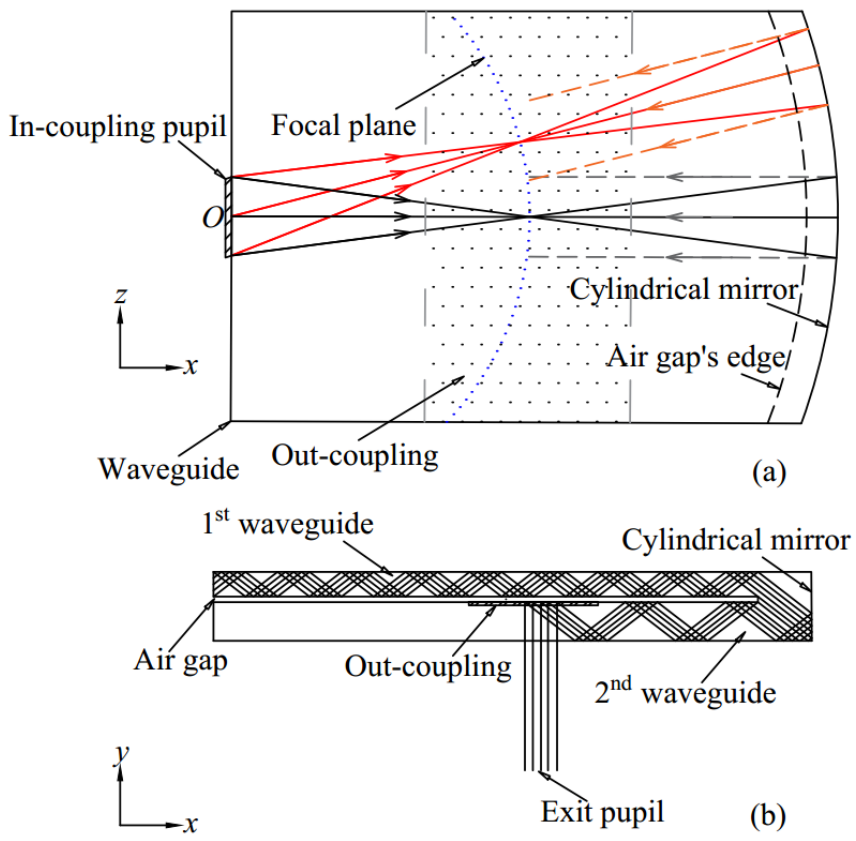

Fig. 2. Schematic for the designed system. (a) Ray path in zx plane. The dashed rays are the rays that are coupled into the second waveguide. (b) Ray path in yx plane. The air gap is magnified for clarity.

For coupling the light from the first waveguide to the second one, the length $L$ of the transition region (filled area with points on Fig. 3) and the thickness of the second waveguide $d_{2}$ are interdependent; both are critical. As shown in Fig. 3, the red arrow lines correspond to the propagating field with minimum tilt angle $(\alpha)$ and the black arrow lines correspond to the field with maximum tilt angle $(\beta)$. In the following we call minimum (resp. maximum) field, the field whose chief ray has the minimum (resp. maximum) tilt angle. As the air gap is very small, it is not represented in the figure. We suppose that the refractive indices of the two waveguides and the transition region are $n_{1}$ and $n_{2}$ respectively. For each field, part of the rays cannot be coupled into the second waveguide. As example it is the case for the chief ray of the maximum field reflected inside the grey area and the chief ray of the minimum field reflected inside the red area. These rays are 
reflected back to the first waveguide, which limits the coupling efficiency.

The side lengths of the filled area along the waveguide are $l_{1}$ for the minimum field and $l_{2}$ for the maximum field. They are given by:

$$
\begin{gathered}
l_{1}=\frac{2}{\tan (\alpha)}\left(d_{1}-\frac{L n_{1} \sin (\alpha)}{\sqrt{n_{2}^{2}-n_{1}^{2} \sin ^{2}(\alpha)}}\right) \\
l_{2}=\frac{2}{\tan (\beta)}\left(\frac{L n_{1} \sin (\beta)}{\sqrt{n_{2}^{2}-n_{1}^{2} \sin ^{2}(\beta)}}-d_{2}\right)
\end{gathered}
$$

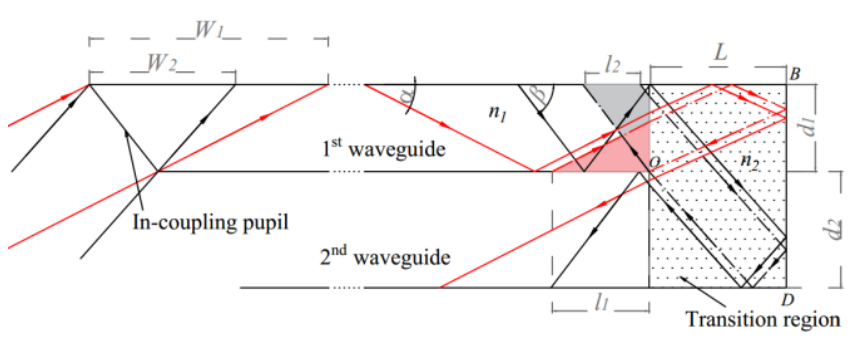

Fig. 3. The ray path of coupling from the first waveguide to the second waveguide.

In the design process we first fix $d_{1}$. Lengths $l_{1}$ and $l_{2}$ should be zero if all the light from the first waveguide is coupled into the second waveguide. The limit value of the length $L$ of the transition region is obtained by setting $l_{1}=0$ :

$$
L=\frac{d_{1} \sqrt{n_{2}^{2}-n_{1}^{2} \sin ^{2}(\alpha)}}{n_{1} \sin (\alpha)} .
$$

The minimum thickness of the second waveguide $d_{2}$ is obtained when $l_{2}=0$ :

$$
d_{2}=\frac{L n_{1} \sin (\beta)}{\sqrt{n_{2}^{2}-n_{1}^{2} \sin ^{2}(\beta)}} .
$$

Combining (3) and (4) we get the minimum value for $d_{2}$ :

$$
d_{2 \min }=\frac{d_{1} \sin (\beta) \sqrt{n_{2}^{2}-n_{1}^{2} \sin ^{2}(\alpha)}}{\sin (\alpha) \sqrt{n_{2}^{2}-n_{1}^{2} \sin ^{2}(\beta)}}
$$

The relations between $d_{2}$ with respect to other parameters can be found in Ref [25]. It would be interesting to reduce the thickness of the second waveguide to decrease the weight and size. This introduces some additional coupling losses. In the following text, the transition region and the two waveguides are assumed to be made with the same material and the thicknesses verify $d_{1}<d_{2}$ in order to avoid high losses. By setting $l_{1}=l_{2}=0$, we get the critical values for $\alpha$ and $\beta$ respectively:

$$
\alpha^{\prime}=\arctan \left(\frac{d_{1}}{L}\right)
$$

$$
\beta^{\prime}=\arctan \left(\frac{d_{2}}{L}\right)
$$

Three situations occur for the coupling from the first waveguide to the second one. In the first one, the field angle lies inside the interval $\left[\alpha, \alpha^{\prime}\right]$ and $l_{l}$ the side length of the red area along the waveguide is given by $\mathrm{Eq}(1)$. In the second situation, when the field angle lies inside the interval $\left[\alpha^{\prime}, \beta^{\prime}\right]$ there is no coupling loss. When the field angle lies inside the interval $\left[\beta^{\prime}, \beta\right], l_{2}$ the side length of the shaded area along the waveguide is determined by $\mathrm{Eq}(2)$. In order to calculate the length of the transition region, as the first case we can set $l_{1}=l_{2}$, then we obtain:

$$
L=\frac{d_{1} \cot (\alpha)+d_{2} \cot (\beta)}{2} .
$$

On Fig. $3 W_{1}$ and $W_{2}$ are the lengths of the waveguide covered by the minimum and the maximum fields. The coupling efficiencies are different if $l_{1}=l_{2}$. To obtain the same coupling efficiency, we need:

$$
\frac{l_{1}}{W_{1}}=\frac{l_{2}}{W_{2}}
$$

In this second case, the length of the transition region is given by:

$$
L=\frac{W_{2} d_{1} \cot (\alpha)+W_{1} d_{2} \cot (\beta)}{W_{1}+W_{2}} .
$$

As an example, using PMMA ( $\mathrm{n}=1.49)$, if we set $d_{1}=1.5 \mathrm{~mm}, d_{2}=2$ $\mathrm{mm}$, we obtain the different parameters shown in table 1 for the two cases.

Table 1. The value of the parameters in two cases (case 1: the lengths $l_{1}$ and $l_{2}$ are equal; case 2 : the same coupling efficiency)

\begin{tabular}{ccc}
\hline Parameters & Case1 & Case2 \\
\hline$L(\mathrm{~mm})$ & 2.3 & 2.2 \\
$\alpha\left(^{\circ}\right)$ & 28 & 28 \\
$\beta\left(^{\circ}\right)$ & 48 & 48 \\
$\alpha^{\prime}\left({ }^{\circ}\right)$ & 33.0 & 34.3 \\
$\beta^{\prime}\left({ }^{\circ}\right)$ & 40.9 & 42.3 \\
$l_{1}(\mathrm{~mm})$ & 1.02 & 1.25 \\
$l_{2}(\mathrm{~mm})$ & 1.02 & 0.8 \\
Coupling efficiency for the minimum field & $74.3 \%$ & $68.6 \%$ \\
Coupling efficiency for the maximum field & $59.7 \%$ & $68.6 \%$ \\
\hline
\end{tabular}

The maximum value of $\beta^{\prime}-\alpha^{\prime}$ which represents the range without loss is $8.2^{\circ}$. The value of $\beta^{\prime}-\alpha^{\prime}$ for the two cases are $7.9^{\circ}$ and $8^{\circ}$ respectively. The differences from the maximum value are very small. The second case offers a better coupling uniformity. Actual efficiency for a specific field could be higher depending of the amount of light falling into the filled regions (Fig. 3). The efficiency for the vertical fields is uniform because the center of the incoupling pupil $O$ is also the center of the cylindrical mirror and the center of the cylindrical edge of the air gap (Fig. 2(a)). Therefore, each vertical field has the same coupling efficiency.

We have designed a system with the presented method and the parameters described above using Zemax. A 0.61 in OLED microdisplay with $852 \times 600$ pixels is used as image source. The 
pixel size is $15 \mu \mathrm{m}$ which corresponds to a Nyquist frequency of 33 $\mathrm{lp} / \mathrm{mm}$. The horizontal FOV is set to $20^{\circ}$. The vertical FOV is $60^{\circ}$. The MTF of the 12 object fields are plotted in Fig. 4(a). They are evaluated with a full rectangular pupil size of $1.9 \mathrm{~mm}(\mathrm{H}) \times 12 \mathrm{~mm}$ (V). All the values are above 0.3 at $33 \mathrm{lp} / \mathrm{mm}$, which is sufficient for a visual system. The vertical and horizontal magnifications are different and in a ratio of 1.6. Fig. 5 shows the grid distortion of the system with respect to the central field. The maximum distortion is $4.5 \%$ at the corner.

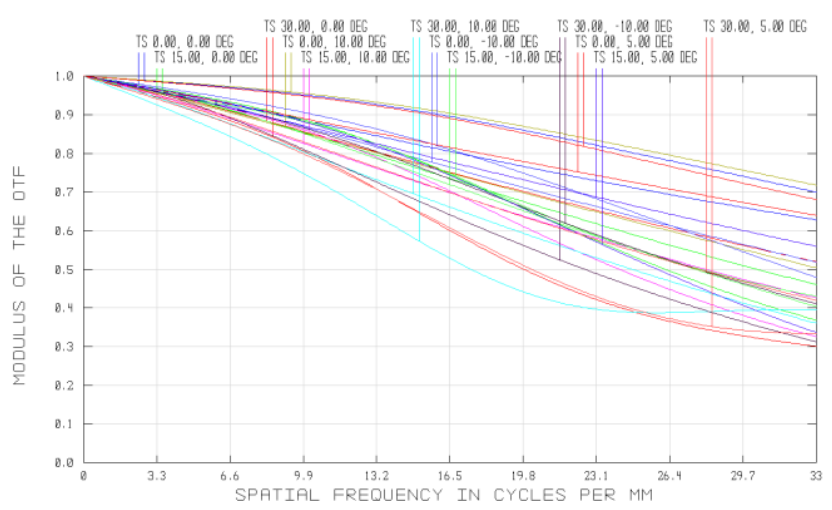

Fig. 4. MTF curves of the system with the 12 evaluated fields in object angle mode. T and S represent the tangential and sagittal MTFs of each field separately.

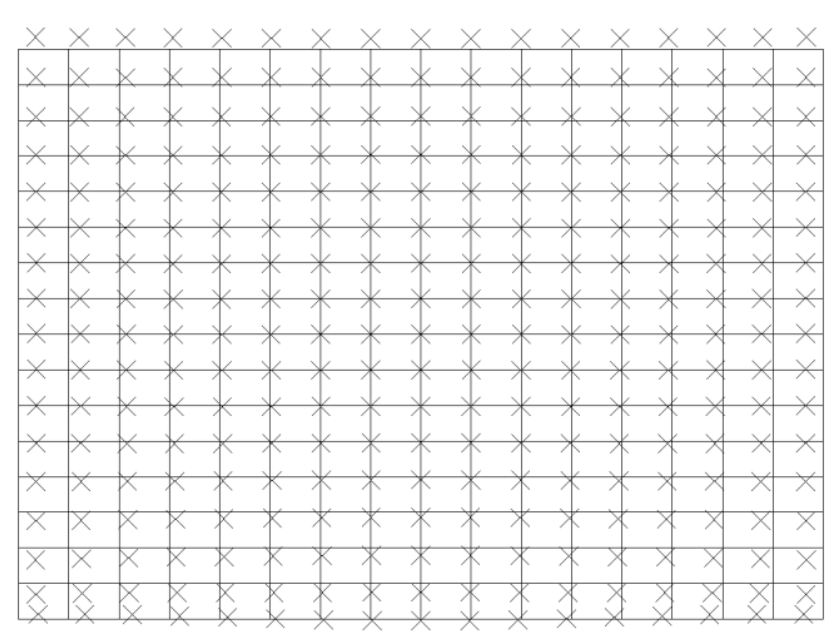

Fig. 5. The grid distortion of the system.

The performance of the system is summarized in the table 2. To estimate the value of the eye box in the horizontal direction a Lumus waveguide type out-coupling system has been used. The weight in table 2 takes into account all the optical components.

Table 2. Performance of the system

\begin{tabular}{cc}
\hline Parameters & Value \\
\hline Field-of-view $(\mathrm{H} \times \mathrm{V})$ & $30^{\circ} \times 60^{\circ}$ \\
In-coupling pupil $(\mathrm{H} \times \mathrm{V}$ mm $)$ & $1.9 \times 12$ \\
Eye box $(\mathrm{H} \times \mathrm{V} \mathrm{mm})$ & $\approx 15 \times 12$ \\
System MTF & 0.3 at $33 \mathrm{lp} / \mathrm{mm}$ \\
Distortion & $<4.5 \%$ \\
Monocular weight $(\mathrm{g})$ & 11 \\
Magnification ratio $(\mathrm{V} / \mathrm{H})$ & 1.6 \\
\hline
\end{tabular}

Figures 4 and 5 show that a good image quality can be expected for the whole FOV. A foreseen difficulty comes from fabrication and testing since the freeform prism has a complex shape. The current way to realize it, is plastic molding injection. A prototype fabrication is still a high cost operation.

In conclusion, we proposed a new polychromatic compact WNED system design by combining a freeform prism and two waveguides. The two waveguides have a cylindrical edge and are separated by a small air gap. The coupling from the first waveguide to the second one has been investigated and optimized. As a result, we obtain an increased FOV of $30^{\circ}(\mathrm{H}) \times 60^{\circ}(\mathrm{V})$ and a very large eye box of about $15 \mathrm{~mm}(\mathrm{H}) \times 12 \mathrm{~mm}(\mathrm{~V})$ allowing large eye movements.

Acknowledgment. Portions of this work were presented at the SPIE Photonics Europe Conference in 2016, Photonics and Digital Technologies for Imaging Applications IV, 989605.

\section{References}

1. J. Rolland and O. Cakmakci, Opt. Photonics News20(4), 20 (2009).

2. A. Travis, U. S. Patent 20130021392 A1

3. M. J. Heinrich and M. I. Olsson, U. S. Patent D659741

4. H. Mukawa, K. Akutsu, I. Matsumura, S. Nakano, T. Yoshida, M. Kuwahara, and K. Aiki, J. Soc. Inf. Disp. 17(3), 185-193 (2009).

5. P. Äyräs, P. Saarikko, and T. Levola, J. Soc. Inf. Disp. 17(8), 659-664 (2009)

6. R. Azuma, Y. Baillot, R. Behringer, S. Feiner, S. Julier, and B. Macintyre, IEEE Comput. Graph. Appl. 21(6), 34-47 (2001).

7. S. Yamazaki, K. Inoguchi, Y. Saito, H. Morishima, and N.Taniguchi, Proc. SPIE 3639, 453 (1999)

8. H. Hua, A. Girardot, C. Gao, and J. P. Rolland, Appl. Opt. 39(22), 3814-3824 (2000).

9. R. Martins, V. Shaoulov, Y. Ha, and J. P. Rolland, Opt. Express 15(22), 14530-14538 (2007).

10. M. Beuret, P. Twardowski, and J. Fontaine, Opt. Express 19(20), 1968819701 (2011)

11. M. M. Bayer, Proc. SPIE 4711, 202 (2002)

12. A. Bauer and J. P. Rolland, Opt. Express 22, 13155-13163 (2014)

13. J. Yang, W. Liu, W. Lv, D. Zhang, F. He, Z. Wei, and Y. Kang, Opt. Lett. 38, 2035-2037 (2013)

14. Y. Amitai, in SID International Symposium Digest of Technical Papers (Society for Information Display), 36, 360-363 (2005)

15. D. Cheng, Y. Wang, C. Xu, W. Song, and G. Jin, Opt. Express 22, 20705 20719 (2014)

16. B. Kress and T. Starner, Proc. SPIE 8720, 87200A (2013)

17. O. Cakmakci and J. Rolland, J. Display Technol. 2(3), 199-216 (2006).

18. Y. Amitai, U. S. Patent 7,672,055 B2

19. G. Dubroca, P. Benot, K. Sarayeddine, X. Hugel, (IDW 2010, Fukuoka, Japan)

20. I. Kasai, Y. Tanijiri, E. Takeshi, and U. Hiroaki, Opt. Rev. 8(4), 241-244 (2001)

21. I. K. Wilmington and M. S. Valera, SID Symposium Digest of Technical Papers, 44: 278-280 (2013)

22. A. A. Cameron, Proc. SPIE 383, 83830E (2012)

23. L. Eisen, M. Meyklyar, M. Golub, A. A. Friesem, I. Gurwich, and V. Weiss, Appl. Opt. 45(17), 4005-4011 (2006)

24. J. Han, J. Liu, X. Yao, and Y. Wang, Opt. Express 23, 3534-3549 (2015)

25. J. Yang, P. Gérard; P. Twardowski; J. Fontaine, Proc. SPIE 9896, (2016). 
Reference

1. J. Rolland and O. Cakmakci, "Head-Worn Displays: The Future Through New Eyes," Opt. Photonics News 20(4), 20 (2009).

2. A. Travis, "Wide field-of-view virtual image projector", U. S. Patent 20130021392 A1

3. M. J. Heinrich and M. I. Olsson, "Wearable display device," U. S. Patent D659741.

4. H. Mukawa, K. Akutsu, I. Matsumura, S. Nakano, T. Yoshida, M. Kuwahara, and K. Aiki, "A full color eyewear display using planar waveguides with reflection volume holograms," J. Soc. Inf. Disp. 17(3), 185-193 (2009)

5. P. Äyräs, P. Saarikko, and T. Levola, "Exit pupil expander with a large field of view based on diffractive optics," J. Soc. Inf. Disp. 17(8), 659-664 (2009).

6. R. Azuma, Y. Baillot, R. Behringer, S. Feiner, S. Julier, and B. Macintyre, "Recent advances in augmented reality," IEEE Comput. Graph. Appl. 21(6), 34-47 (2001)

7. Yamazaki, K. Inoguchi, Y. Saito, H. Morishima, N. Taniguchi, Thin widefield-of-view HMD with free-form-surface prism and applications, Proc. SPIE 3639, p. 453, 1999. doi:10.1117/12.349411

8. H. Hua, A. Girardot, C. Gao, and J. P. Rolland, "Engineering of headmounted projective displays," Appl. Opt. 39(22), 3814-3824 (2000)

9. R. Martins, V. Shaoulov, Y. Ha, and J. P. Rolland, “A mobile head-worn projection display," Opt. Express 15(22), 14530-14538 (2007).

10. M. Beuret, P. Twardowski, and J. Fontaine, "Design of an off-axis seethrough display based on a dynamic phase correction approach," Opt. Express 19(20), 19688-19701 (2011)

11. M. M. Bayer, "Retinal scanning display: a novel HMD approach for army aviation," Proc. SPIE 4711, 202 (2002).

12. A. Bauer and J. Rolland, "Visual space assessment of two all-reflective, freeform, optical see-through head-worn displays," Opt. Express 22, 13155-13163 (2014).

13. Jianming Yang, Weiqi Liu, Weizhen Lv, Daliang Zhang, Fei He, Zhonglun Wei, and Yusi Kang, "Method of achieving a wide field-of-view headmounted display with small distortion," Opt. Lett. 38, 2035-2037 (2013)

14. Y. Amitai, "Extremely compact high-performance HMDs based on substrate-guided optical element," in Society for Information Display (SID) International Symposium Digest (Society for Information Display, 2004), Vol. 35, No. 1, pp. 310-313.

15. Dewen Cheng, Yongtian Wang, Chen Xu, Weitao Song, and Guofan Jin, "Design of an ultra-thin near-eye display with geometrical waveguide and freeform optics," Opt. Express 22, 20705-20719 (2014)

16. B. Kress and T. Starner, "A review of head-mounted displays (HMD) technologies and applications for consumer electronics," Proc. SPIE 8720, 87200A (2013).

17. Ozan Cakmakci and Jannick Rolland, "Head-Worn Displays: A Review," J. Display Technol. 2, 199-216 (2006)

18. Yaakov Amitai, "Substrate-guided optical devices," U. S. Patent 7,672,055 B2.

19. G. Dubroca, P. Benot, K. Sarayeddine, X. Hugel, Monolithic Low Cost Plastic Guide for Full Colour See-Through Personal Video Glasses (IDW 2010, Fukuoka, Japan)

20. I. Kasai, Y. Tanijiri, E. Takeshi, and U. Hiroaki, "A practical see-through head mounted display using a holographic optical element," Opt. Rev. 8(4), 241-244 (2001).

21. I. K. Wilmington and M. S. Valera, "Waveguide - Based Display Technology” , SID Symposium Digest of Technical Papers, 44: 278 280 (2013).

22. A. A. Cameron, "Optical waveguide technology and its application in head-mounted displays," Proc. SPIE 383, 83830E (2012).

23. L. Eisen, M. Meyklyar, M. Golub, A. A. Friesem, I. Gurwich, and V. Weiss, "Planar configuration for image projection," Appl. Opt. 45(17), 40054011 (2006)
24. Jian Han, Juan Liu, Xincheng Yao, and Yongtian Wang, "Portable waveguide display system with a large field of view by integrating freeform elements and volume holograms," Opt. Express 23, 35343549 (2015)

25. Yang Jianming; Philippe Gérard; Patrice Twardowski; Joël Fontaine; Polychromatic see-through near-eye display design with two waveguides and a large field-of-view Proc. SPIE 9896, Optics, Photonics and Digital Technologies for Imaging Applications IV, 989605 (April 29, 2016); doi:10.1117/12.2227383. 